\title{
The identification and epidemiology of meticillin-resistant Staphylococcus aureus and Clostridium difficile in patient rooms and the ward environment
}

\author{
Meredith C Faires ${ }^{1 *}$, David L Pearl ${ }^{1}$, Olaf Berke ${ }^{1,2}$, Richard J Reid-Smith ${ }^{1,3}$ and J Scott Weese ${ }^{3}$
}

\begin{abstract}
Background: Research has indicated that the environment may play an important role in the transmission of meticillin-resistant Staphylococcus aureus (MRSA) and Clostridium difficile in healthcare facilities. Despite the significance of this finding, few data exist from longitudinal studies investigating MRSA and C. difficile contamination, concurrently, in both patient rooms and the general ward environment. The objectives of this study were to determine the prevalence of MRSA and C. difficile contamination in patient rooms and the ward environment and identify risk factors associated with a surface being contaminated with these pathogens.
\end{abstract}

Methods: Environmental surfaces in patient rooms and the general environment in the medical and surgical wards of a community hospital were sampled six times over a 15 week period. Sterile electrostatic cloths were used for sampling and information pertaining to the surface sampled was recorded. MRSA isolates and C. difficile specimens were obtained from hospitalized patients.

Enrichment culture was performed and spa typing or ribotyping was conducted for MRSA or C. difficile, respectively. Exact logistic regression models were constructed to examine risk factors associated with MRSA and $\mathrm{C}$. difficile contamination.

Results: Sixteen (41\%) patient rooms had $\geq 1$ surfaces contaminated with MRSA and/or C. difficile. For 218 surfaces investigated, 3.2\% and 6.4\% were contaminated with MRSA or C. difficile, respectively. Regression models indicated that surfaces in rooms exposed to a $C$. difficile patient had significantly increased odds of being contaminated with $C$. difficile, compared to surfaces in unexposed patient rooms. Additionally, compared to plastic surfaces, cork surfaces had significantly increased odds of being contaminated with C. difficile. For 236 samples collected from the ward environment, MRSA and C. difficile were recovered from $2.5 \%$ and $5.9 \%$ of samples, respectively. Overall, the majority of MRSA and C. difficile strains were molecularly identified as spa type $2 / \mathrm{t} 002(84.6 \%, n=11)$ and ribotype $078(50 \%, n=14)$, respectively.

Conclusions: In patient rooms and the ward environment, specific materials and locations were identified as being contaminated with MRSA or C. difficile. These sites should be cleaned and disinfected with increased vigilance to help limit the transmission and dissemination of MRSA and C. difficile within the hospital.

Keywords: Meticillin-resistant Staphylococcus aureus, Clostridium difficile, Epidemiology, Environment, Hospital, Ward, Patient rooms, Risk factors, Ribotype 078

\footnotetext{
*Correspondence: mfaires@uoguelph.ca

'Department of Population Medicine, University of Guelph, Guelph, ON, Canada

Full list of author information is available at the end of the article
}

\section{Biomed Central}

(c) 2013 Faires et al.; licensee BioMed Central Ltd. This is an Open Access article distributed under the terms of the Creative Commons Attribution License (http://creativecommons.org/licenses/by/2.0), which permits unrestricted use, distribution, and reproduction in any medium, provided the original work is properly cited. 


\section{Background}

In Canadian hospitals, the incidence of meticillinresistant Staphylococcus aureus (MRSA) infections and colonization have increased 17-fold from 1995 to 2007 [1] and remains a leading cause for a range of opportunistic infections [1]. Similarly, Clostridium difficile infection (CDI) has also increased in incidence and severity including a four-fold increase in attributed mortality [2], and is the most commonly diagnosed cause of healthcare-associated (HA) and antimicrobial-associated diarrhea [3].

Patients are the main reservoirs of both these pathogens, but there is increasing evidence that the environment may play a significant role in the nosocomial transmission of MRSA [4] and C. difficile [5]. The ability of contaminated surfaces contributing to the transmission of nosocomial pathogens relies on several determinants including the frequency at which surfaces are contaminated, if levels of contamination are sufficiently high to result in transmission, and the ability of pathogens to remain viable on various surfaces [6]. Research has demonstrated that $S$. aureus [7] and C. difficile spores [8] are able to survive and persist in the hospital environment for months. As levels of environmental contamination with these HA pathogens increase, the prevalence of healthcare worker hand carriage also increases $[9,10]$. Additionally, patients and visitors may be contaminated from contaminated surfaces, creating further potential for acquisition or transmission of MRSA and $C$. difficile in the healthcare setting and the community.

Studies investigating contamination of hospital surfaces have primarily focused on MRSA or C. difficile. There has been limited research investigating environmental contamination with both of these pathogens, concurrently, in healthcare facilities. Furthermore, potential associations or commonalities between environmental contamination with MRSA and C. difficile, in both patient rooms and the ward environment have not been explored. Given the different sources of MRSA and C. difficile contamination, nasal/wound versus fecal, and different susceptibility to disinfectants, an understanding of the epidemiology of MRSA and C. difficile in the environment, in parallel study, can help infer sources of contamination and potential factors associated with contamination. Subsequently, the data obtained from this research can be used by hospital personnel to evaluate hospital infection protocols and procedures.

The objectives of this investigation were to determine the prevalence and identify risk factors associated with MRSA and C. difficile contamination in patient rooms and the general ward environment of a community hospital and compare MRSA and C. difficile strains between patients and the contaminated environment.

\section{Methods}

\section{Study site}

The participating healthcare facility is a 260-bed large community hospital located in Ontario, Canada. Starting in December 2010, environmental sampling of patient rooms and the general hospital environment in the medical and surgical wards was conducted during six visits over a 15 week period. Sampling was conducted once a week for three consecutive weeks during weeks 1-3 (visits 1-3) and weeks 13-15 (visits 4-6). During the study period, the MRSA colonization and infection rate ranged from 0.38 - 1.93 cases $/ 1,000$ patient days and the CDI rate ranged from $0.19-0.83$ cases $/ 1,000$ patient days. Although a C. difficile outbreak did not occur during the study period, the hospital did experience an MRSA outbreak between weeks 8 and 13 and an influenza outbreak between weeks 9 and 11 . However, both outbreaks occurred in wards not involved in this investigation. For environmental sampling in patient rooms, verbal consent from patients, or from a parent in the case of a child, was required prior to sampling. Written informed consent was not required as surfaces sampled in patient rooms belonged to the hospital and sampling of patient's personal belongings was not conducted. The University of Guelph and the hospital research ethics boards approved this study.

\section{Sampling}

Sampling of environmental surfaces was conducted in patient rooms and the ward environment of one surgical ward and two medicine wards, identified as medicine A and medicine B. Three different types of patient rooms were sampled for contamination. An unexposed room had a patient not identified with MRSA or CDI and was not under isolation precautions. A C. difficile exposed room had a patient identified with CDI, based on clinical signs and a positive stool toxin ELISA test (Tox A/B Quik Chek, TechLab, Blacksburg, Virginia, USA), and was under isolation precautions. An MRSA exposed room had a patient identified with an MRSA infection and/or colonization, based on microbiological diagnosis, and was under isolation precautions. In the participating hospital, surveillance for MRSA is conducted based on recommendations provided by a Provincial Infectious Disease Advisory Committee [11]. Briefly, at the time of hospital admission, patients identified as having an increased risk for MRSA acquisition (e.g., specific risk factors, wounds, incisions, catheter sites) are screened. For patients located on high risk units (e.g., intensive care unit), universal admission screening is performed. During hospitalization, surveillance cultures are not routinely conducted. Furthermore, screening of catheter sites are performed only if clinical signs of infection are 
observed or the patient is transferred to the continuing care or rehabilitation wards.

For each MRSA and $C$. difficile exposed room that was identified, two unexposed rooms were randomly sampled on the same ward as the exposed room. In all patient rooms, six different surfaces were sampled including the railing at the end of the bed, bulletin board, chair back, overbed table, privacy curtain, and television. For unexposed rooms, if more than one patient was present, the investigator randomly chose a patient and sampled the surfaces in that patient's vicinity. For the general ward environment, environmental surfaces sampled were those distributed over the ward and located in nursing and physician work areas, hallways, and visiting rooms. Surfaces were sampled 4-6 times over the study period and prior to being cleaned by housekeeping staff. In the participating facility, surfaces located in the general ward environment and patient rooms (excluding $C$. difficile exposed rooms), were cleaned once a day using a quaternary ammonium compound. In $C$. difficile exposed rooms, surfaces were cleaned twice a day with bleach. Following discharge, all patient rooms were subjected to a terminal clean with a quaternary ammonium compound. In addition, $C$. difficile exposed rooms were cleaned with bleach. No changes in the hospital cleaning protocol on the surgical and medicine wards were instituted during the study period.

Sterile electrostatic cloths (Swiffer ${ }^{\mathrm{Tm}}$, Proctor and Gamble, USA) were used for environmental sampling. Using a gloved hand, the investigator wiped the electrostatic cloth over half the environmental surface to be sampled, up to a maximum of $20 \mathrm{~cm} \times 20 \mathrm{~cm}$. The cloth was then placed in a sterile collection bag (Whirl-Pak ${ }^{\ominus}, \mathrm{Nasco}$, California, USA). The investigator then used a second cloth to sample the other half of the environmental surface. Gloves were changed between each sampling. During each visit, two electrostatic cloths were not used for sampling but were handled and processed in parallel, to act as negative controls. Information collected with each surface sampled included: visit number, hospital ward, surface location, environmental surface sampled, and type of surface material. From the hospital's microbiology laboratory, patient isolates identified as MRSA were collected from culture plates using a culture swab with Stuart's media and stool samples from $C$. difficile patients were also obtained. Isolates or specimens were obtained from only patients that were hospitalized in the medicine and surgical wards during the 15 week study period, irrespective of whether they were present in the wards on the sampling date. Only one isolate per patient was analyzed. Isolates from patients that were epidemiologically linked to the MRSA outbreak were not collected. All specimens submitted for MRSA or C . difficile testing were collected at the discretion of medical personnel.

\section{Processing}

For MRSA, cloths were immersed in $30 \mathrm{ml}$ of enrichment broth containing sodium chloride $(75 \mathrm{~g} / \mathrm{L})$, mannitol $(10 \mathrm{~g} / \mathrm{L})$, tryptone $(10 \mathrm{~g} / \mathrm{L})$, and yeast extract $(2.5 \mathrm{~g} / \mathrm{L})$ and incubated at $35^{\circ} \mathrm{C}$, aerobically, for 24 hours. Following incubation, a $5 \mu \mathrm{L}$ aliquot of broth was inoculated onto MRSA Chromogenic agar (BBL CHROMagar MRSA, Becton, Dickinson and Company, Sparks, Maryland, USA) and incubated, aerobically, at $35^{\circ} \mathrm{C}$ for $24-48$ hours. Isolates were identified as $S$. aureus by Gram stain, tube coagulase test, catalase test, and the $S$. aureus latex agglutination assay (Pastorex Staph-plus, Bio-Rad Laboratories Ltd., Mississauga, Ontario, Canada). Meticillin-resistance was confirmed by testing for the penicillin-binding protein 2a (MRSA Screening Kit, Denka Seiken, Campbell, California, USA). For patient isolates, culture swabs were streaked onto blood agar (Oxoid, Nepean, Ontario, Canada) and processed as described above. Molecular typing of MRSA was conducted using sequence analysis of the $\mathrm{X}$ region of the staphylococcal protein A gene (spa typing) [12]. Sequences were analyzed using the eGenomics software [13] and the Ridom system [14]. For eGenomics, spa types are reported using a numerical system (e.g., spa type 2) whereas Ridom spa types are reported using a numerical system preceded by a ' $t$ ' (e.g., t002). All spa types were compared to epidemic MRSA strains that are commonly found in Canada [15]. These Canadian epidemic MRSA strains are designated as CMRSA and should not be confused with community-associated MRSA strains which are designated as CA-MRSA. All MRSA isolates were investigated for the lukF-PV gene encoding the Panton-Valentine leukocidin toxin by real-time PCR [16]. Molecular typing of the MRSA outbreak strain was not conducted by the hospital.

For $C$. difficile, electrostatic cloths were immersed in $30 \mathrm{ml}$ of enrichment broth containing brain-heart infusion $(37 \mathrm{~g} / \mathrm{L})$ and $0.1 \%$ sodium taurocholate and incubated at $37^{\circ} \mathrm{C}$, anaerobically, for 5 days. A $2 \mathrm{ml}$ sample of broth was then alcohol shocked for one hour, followed by centrifugation at 4,000 rpm for 10 minutes. The resulting pellet was inoculated onto $C$. difficile moxalactam-norfloxacin agar (Oxoid, Nepean, Ontario, Canada) and incubated for $24-96$ hours at $37^{\circ} \mathrm{C}$, anaerobically. Colonies were confirmed as $C$. difficile based on characteristic morphology, odour, and production of Lproline-aminopeptidase (Prodisk, Remel, Lenexa, Kansas, USA). For patient isolates, approximately $1 \mathrm{~g}$ of feces was inoculated into $9 \mathrm{ml}$ of enrichment broth and processed as described previously. All isolates identified as C. difficile were investigated for the presence of toxin $\mathrm{A}(t c d A)$ [17], toxin $B(t c d B)$ [18], and the binary toxin $(c d t A)$ [19] genes using PCR. Ribotyping was used to analyze all $C$. difficile isolates [20]. When a ribotype pattern was identified as an 
international ribotype based on comparison to reference strains, the appropriate numerical designation (e.g., 027) was assigned. Alternatively, an internal laboratory designation was assigned. Toxinotyping [21] was also performed on a representative of each toxigenic ribotype.

\section{Statistical analysis}

For patient rooms and the general ward environment, the prevalence of MRSA and C. difficile contamination was determined for ward, location, surface material, surface sampled, and visit (ward only). Statistical models were also constructed, using exact logistic regression, to test for associations between the occurrence of environmental contamination with MRSA or C. difficile and the following predictor variables: ward, location, surface material, surface sampled, and visit number (ward only). Additionally, the overall prevalence of surfaces positive for MRSA or C. difficile prior to (visits 1-3), and following (visits 4-6), the MRSA and influenza outbreaks, were compared using exact logistic regression. The Spearman's rank correlation test was used to identify correlations between all independent variables. Variables with a correlation of $>0.8$ were investigated and only the variable that was more biologically plausible was included in the model to avoid issues associated with collinearity [22]. Due to the relatively low prevalence of MRSA and $C$. difficile contamination in both patient rooms and the ward environment, only univariable models were constructed using exact logistic regression, employing the score method to calculate the P-value [23]. Compared to other computational methods, the score method does not compute an equivalent confidence interval; subsequently, only odds ratios (OR) and $\mathrm{P}$-values are presented. For significant independent variables with several categories, contrasts between categories were also examined. Descriptive statistics and analyses were performed using Stata 11.0 (StataCorp LP, College Station, Texas, USA). All tests were two-sided and the significance level was selected at $\alpha=0.05$.

\section{Results}

Patient rooms

A total of 218 surfaces located in 26 unexposed rooms, 10 MRSA exposed rooms, and 3 C. difficile exposed rooms, were sampled during the study period. The prevalence of MRSA and $C$. difficile contamination in each type of patient room by ward, surface material, and surface sampled is presented in Table 1. Overall, the highest prevalence of MRSA contamination occurred in unexposed rooms and the highest prevalence of $C$. difficile

Table 1 Descriptive statistics of variables for MRSA and C. difficile contamination in patient rooms

\begin{tabular}{|c|c|c|c|c|c|c|c|c|}
\hline \multirow[b]{2}{*}{ Variables $^{\mathrm{a}}$} & \multicolumn{2}{|c|}{ Unexposed rooms $(n=26)$} & \multicolumn{2}{|c|}{ MRSA exposed rooms $(n=10)$} & \multicolumn{2}{|c|}{ C. difficile exposed rooms $(n=3)$} & \multicolumn{2}{|c|}{ Overall Prevalence } \\
\hline & MRSA (\%) & C. difficile (\%) & MRSA (\%) & C. difficile (\%) & MRSA (\%) & C. difficile (\%) & MRSA (\%) & C. difficile (\%) \\
\hline General prevalence & $6 / 149(4.0)$ & $9 / 149(6.0)$ & $1 / 52(1.9)$ & $1 / 52(1.9)$ & $0 / 17(0)$ & $4 / 17(23.5)$ & $7 / 218(3.2)$ & $14 / 218(6.4)$ \\
\hline \multicolumn{9}{|l|}{ Ward: } \\
\hline Medicine $A^{b}$ & $4 / 54(7.4)$ & $3 / 54(5.6)$ & $0 / 20(0)$ & $1 / 20(5.0)$ & $0 / 5(0)$ & $2 / 5(40)$ & $4 / 79(5.1)$ & $6 / 79(7.6)$ \\
\hline Medicine $B^{c}$ & 0/35 (0) & 3/35 (8.6) & $1 / 16(6.3)$ & $0 / 16(0)$ & No sampling & No sampling & $1 / 51(1.9)$ & $3 / 51(5.9)$ \\
\hline Surgery ${ }^{d}$ & $2 / 60(3.3)$ & $3 / 60(5.0)$ & 0/16 (0) & 0/16 (0) & $0 / 12(0)$ & $2 / 12(16.7)$ & 2/88 (2.3) & $5 / 88(5.7)$ \\
\hline \multicolumn{9}{|l|}{ Material type: } \\
\hline Cork & $0 / 23(0)$ & $3 / 23(13)$ & $0 / 7(0)$ & $1 / 7(14.3)$ & $0 / 3(0)$ & $2 / 3(66.7)$ & $0 / 33(0)$ & $6 / 33(18.2)$ \\
\hline Fabric & $0 / 26(0)$ & $0 / 26(0)$ & $1 / 8(12.5)$ & $0 / 8(0)$ & $0 / 2(0)$ & $0 / 2(0)$ & $1 / 36(2.8)$ & 0/36 (0) \\
\hline Laminate & $1 / 26(3.8)$ & 1/26 (3.8) & $0 / 9(0)$ & $0 / 9(0)$ & $0 / 3(0)$ & 1/3 (33.3) & 1/38 (2.6) & 2/38 (5.3) \\
\hline Plastic & $5 / 74(6.8)$ & 5/74 (6.8) & $0 / 28(0)$ & $0 / 28(0)$ & $0 / 9(0)$ & $1 / 9(11.1)$ & $5 / 111(4.5)$ & 6/111 (5.4) \\
\hline \multicolumn{9}{|l|}{ Surface sampled: } \\
\hline Bulletin board ${ }^{e}$ & $0 / 23(0)$ & $3 / 23(13)$ & $0 / 7(0)$ & $1 / 7(14.3)$ & $0 / 3(0)$ & $2 / 3(66.7)$ & 0/33 (0) & $6 / 33(18.2)$ \\
\hline Chair back $^{\mathrm{e}}$ & $4 / 25(16)$ & $2 / 25(8)$ & $0 / 10(0)$ & $0 / 10(0)$ & $0 / 3(0)$ & $0 / 3(0)$ & $4 / 38(10.5)$ & 2/38 (5.3) \\
\hline End of bed & $1 / 26(3.8)$ & $1 / 26(3.8)$ & 0/10 (0) & $0 / 10(0)$ & $0 / 3(0)$ & $1 / 3(33.3)$ & $1 / 39(2.6)$ & 2/39 (5.1) \\
\hline Overbed table $e^{e}$ & $1 / 26(3.8)$ & $1 / 26(3.8)$ & $0 / 9(0)$ & $0 / 9(0)$ & $0 / 3(0)$ & $1 / 3(33.3)$ & $1 / 38(2.6)$ & 2/38 (5.3) \\
\hline Privacy curtain ${ }^{\mathrm{e}}$ & 0/26 (0) & 0/26 (0) & $1 / 8(12.5)$ & $0 / 8(0)$ & $0 / 2(0)$ & $0 / 2(0)$ & $1 / 36(2.8)$ & 0/36 (0) \\
\hline Television ${ }^{\mathrm{e}}$ & $0 / 23(0)$ & $2 / 23(8.7)$ & $0 / 8(0)$ & $0 / 8(0)$ & $0 / 3(0)$ & $0 / 3(0)$ & $0 / 34(0)$ & 2/34 (5.9) \\
\hline
\end{tabular}

$\mathrm{n}=$ number of rooms.

${ }^{a}$ Denominator is based on the number of surfaces in patient rooms that were tested.

b Total of 10 unexposed rooms, 4 MRSA exposed rooms, $1 \mathrm{C}$. difficile exposed room located in ward Medicine A.

c Total of 6 unexposed rooms, 3 MRSA exposed rooms, 0 C. difficile exposed rooms located in ward Medicine B.

d Total of 10 unexposed rooms, 3 MRSA exposed rooms, 2 C. difficile exposed rooms located in the surgical ward.

e Surfaces were not present in all patient rooms at the time of sampling. 
contamination occurred in $C$. difficile exposed rooms. A total of 12 (46.2\%) unexposed rooms were previously occupied by a MRSA patient. However, none of the surfaces in these 12 rooms were contaminated with MRSA. During the study period, none of the unexposed rooms were previously occupied by a $C$. difficile patient.

Seven MRSA isolates were recovered from patient rooms in which two different spa types were identified; both consistent with the CMRSA-2 strain (Table 2). For C. difficile, four different ribotypes were identified among the 14 isolates recovered, including internationally recognized ribotypes $027(n=1)$ and $078(n=9)$ (Table 3).

For six patient rooms, more than one surface was contaminated with MRSA or C. difficile at the time of sampling. One unexposed room had MRSA recovered on two surfaces, with both MRSA isolates identified as spa type $2 /$ t002. For two unexposed rooms and two C. difficile exposed rooms, $C$. difficile was recovered from two surfaces at the time of sampling. In three of these patient rooms, the $C$. difficile isolates recovered from the two surfaces were molecularly indistinguishable and were identified as ribotype 078 .

Results from the univariable analyses (Table 4) indicated that the odds of a surface being contaminated with
C. difficile were significantly greater in a $C$. difficile exposed room compared to an unexposed room. In addition, in patient rooms, the odds of a cork surface being contaminated with $C$. difficile were significantly greater than surfaces covered in plastic. For the dependent variable, surfaces contaminated with $C$. difficile, statistically significant contrasts were identified between $C$. difficile exposed patient rooms versus MRSA exposed patient rooms ( $\mathrm{OR}$ 14.88; $\mathrm{P}=0.012$ ) and cork surfaces versus fabric surfaces (OR 10.33; $\mathrm{P}=0.009)$. For MRSA contamination of surfaces in patient rooms, no variables were identified as statistically significant.

\section{General environment}

Over the study period, 45 different environmental surfaces, for a total of 236 samples, were investigated for MRSA and $C$. difficile contamination. On average, each surface was sampled 5.2 times (range 4-6). Overall, 2.5\% $(n=6)$ and $5.9 \%(n=14)$ of surfaces were contaminated with MRSA and $C$. difficile, respectively. During the study period, none of the control electrostatic cloths tested positive for MRSA or C. difficile.

Data pertaining to the distribution of MRSA and C. difficile contamination per ward, surface location, surface

Table 2 Typing data for MRSA strains from patients and contaminated surfaces

\begin{tabular}{|c|c|c|c|c|c|}
\hline spa type ${ }^{a}$ & Number of isolates & Ridom spa type ${ }^{b}$ & PVL gene & CMRSA & USA equivalent \\
\hline Patient rooms: & $(n=7)$ & & & & \\
\hline $2^{c}$ & $85.7 \%(6)$ & t002 & No & 2 & 100 \\
\hline $437^{d}$ & $14.3 \%(1)$ & t003 & No & 2 & 100 \\
\hline General environment: & $(n=6)$ & & & & \\
\hline 2 & $83.3 \%(5)$ & t002 & No & 2 & 100 \\
\hline 1 & $16.7 \%(1)$ & t008 & Yes & 10 & 300 \\
\hline Patients $\mathrm{e}$ : & $(n=46)$ & & & & \\
\hline $2^{f}$ & $65.2 \%(30)$ & t002 & No & 2 & 100 \\
\hline 437 & $13 \%(6)$ & t003 & No & 2 & 100 \\
\hline $\mathrm{New}^{g}$ & $6.5 \%(3)$ & Not assigned & No & Not assigned & Not assigned \\
\hline 1 & $4.3 \%(2)$ & t008 & Yes & 10 & 300 \\
\hline 7 & $2.2 \%(1)$ & Not assigned & No & Not assigned & Not assigned \\
\hline 12 & $2.2 \%(1)$ & t062 & No & 2 & 100 \\
\hline 23 & $2.2 \%(1)$ & t548 & No & 2 & 100 \\
\hline $771^{\mathrm{h}}$ & $2.2 \%(1)$ & $\mathrm{t} 2104$ & Yes & Not assigned & Not assigned \\
\hline New & $2.2 \%(1)$ & t3618 & No & Not assigned & Not assigned \\
\hline
\end{tabular}

$\mathrm{n}=$ number of isolates.

$\mathrm{PVL}=$ Panton-Valentine leukocidin.

CMRSA = Canadian epidemic meticillin-resistant Staphylococcus aureus.

a spa types classified according to eGenomics (http://tools.egenomics.com).

b spa types classified according to the Ridom system (http://www.spaserver.ridom.de).

c Five isolates recovered from five unexposed rooms; one isolate recovered from one MRSA exposed room.

${ }^{\mathrm{d}}$ One isolate recovered from one unexposed room.

e For three MRSA exposed rooms, the patient's MRSA isolate was not collected.

${ }^{f}$ Five MRSA isolates are from MRSA exposed rooms that were sampled.

${ }^{g}$ One patient isolate from a MRSA exposed room.

${ }^{\mathrm{h}}$ Patient isolate from a MRSA exposed room. 
Table 3 Typing data for $C$. difficile strains from patients and contaminated surfaces

\begin{tabular}{|c|c|c|c|}
\hline Ribotype & $\begin{array}{l}\text { Number } \\
\text { of isolates }\end{array}$ & Toxinotype & Toxin genes \\
\hline Patient rooms: & $(n=14)$ & & \\
\hline $078^{\mathrm{a}}$ & $64.3 \%(9)$ & V & $t c d A, t c d B, c d t A$ \\
\hline $\mathrm{MOH}-\mathrm{Al} \mathrm{b}^{\mathrm{b}}$ & $21.4 \%(3)$ & 0 & $t c d A, t c d B$ \\
\hline $027^{c}$ & $7.1 \%(1)$ & III & $t c d A, t c d B, c d t A$ \\
\hline $\mathrm{MOH}-\mathrm{V}^{\mathrm{c}}$ & $7.1 \%(1)$ & 0 & $t c d A, t c d B$ \\
\hline General environment: & $(n=14)$ & & \\
\hline 078 & $35.7 \%(5)$ & V & $t c d A, t c d B, c d t A$ \\
\hline 027 & $14.3 \%(2)$ & III & $t c d A, t c d B, c d t A$ \\
\hline $\mathrm{MOH}-\mathrm{V}$ & $14.3 \%(2)$ & 0 & $t c d A, t c d B$ \\
\hline 001 & $7.1 \%(1)$ & 0 & $t c d A, t c d B$ \\
\hline $\mathrm{MOH}-\mathrm{AG}$ & $7.1 \%(1)$ & 0 & $t c d A, t c d B$ \\
\hline $\mathrm{MOH}-\mathrm{T}$ & $7.1 \%(1)$ & 0 & $t c d A, t c d B$ \\
\hline $\mathrm{MOH}-\mathrm{U}$ & $7.1 \%(1)$ & 0 & $t c d A, t c d B$ \\
\hline UNK-2 & $7.1 \%(1)$ & Not tested & None \\
\hline Patients ${ }^{\mathrm{d}}$ : & $(n=21)$ & & \\
\hline $027^{e}$ & $33.3 \%(7)$ & III & $t c d A, t c d B, c d t A$ \\
\hline $\mathrm{MOH}-\mathrm{C}$ & $14.3 \%(3)$ & IX & $t c d A, t c d B, c d t A$ \\
\hline CHP-A ${ }^{f}$ & $9.5 \%(2)$ & XXIV & $t c d A, t c d B, c d t A$ \\
\hline $\mathrm{MOH}-\mathrm{AD}$ & $9.5 \%(2)$ & III & $t c d A, t c d B, c d t A$ \\
\hline 078 & $4.8 \%(1)$ & V & $t c d A, t c d B, c d t A$ \\
\hline $\mathrm{CHP}-\mathrm{C}$ & $4.8 \%(1)$ & XXIV & $t c d A, t c d B, c d t A$ \\
\hline CHP-D & $4.8 \%(1)$ & 0 & $t c d A, t c d B$ \\
\hline $\mathrm{MOH}-\mathrm{M}$ & $4.8 \%(1)$ & 0 & $t c d A, t c d B$ \\
\hline $\mathrm{MOH}-\mathrm{Q}$ & $4.8 \%(1)$ & $X \|$ & $t c d A, t c d B$ \\
\hline $\mathrm{MOH}-\mathrm{V}$ & $4.8 \%(1)$ & 0 & $t c d A, t c d B$ \\
\hline $\mathrm{MOH}-\mathrm{Y}$ & $4.8 \%(1)$ & III & $t c d A, t c d B, c d t A$ \\
\hline
\end{tabular}

$n$ number of isolates.

$\operatorname{tcd} A=$ toxin $\mathrm{A}$.

$\operatorname{tcd} B=$ toxin $B$.

$c d t A=$ binary toxin.

${ }^{\text {a }}$ One isolate from four different unexposed rooms; one isolate from one

MRSA exposed room; two isolates each from two different $C$. difficile exposed rooms.

${ }^{b}$ Isolates from two different unexposed rooms.

c Isolate from one unexposed room.

${ }^{\mathrm{d}}$ For one $C$. difficile exposed room, $C$. difficile could not be isolated from the patient's specimen

e One patient isolate from a $C$. difficile exposed room.

${ }^{f}$ One patient isolate from a $C$. difficile exposed room.

material, and surface sampled are presented in Table 5 . Overall, the highest numbers of surfaces contaminated with MRSA or $C$. difficile were located in nursing and physician work areas or the hallway. Specifically, chairs and counter tops were found to be contaminated with MRSA. For $C$. difficile, surfaces identified with the most contamination included chairs, computer keyboards, and heating oven handles. However, no surfaces had increased odds of contamination compared to other
Table 4 Univariable regression analyses of variables associated with MRSA or C. difficile contamination in patient rooms

\begin{tabular}{|c|c|c|c|c|}
\hline Variable & Description & OR & P-value & $\begin{array}{c}\text { Overall } \\
\text { P-value for } \\
\text { the variable }\end{array}$ \\
\hline \multicolumn{5}{|l|}{$\begin{array}{c}\text { Dependent } \\
\text { variable: surface } \\
\text { contaminated } \\
\text { with MRSA } \\
\end{array}$} \\
\hline \multirow[t]{3}{*}{ Ward } & Medicine A & Referent & & 0.614 \\
\hline & Medicine B & 0.38 & 0.648 & \\
\hline & Surgery & 0.44 & 0.423 & \\
\hline \multirow{3}{*}{$\begin{array}{c}\text { Type of } \\
\text { patient room }\end{array}$} & Unexposed & Referent & & 0.594 \\
\hline & MRSA exposed & 0.47 & 0.679 & \\
\hline & C. difficile exposed & $1.06^{\mathrm{a}}$ & 0.634 & \\
\hline \multirow[t]{4}{*}{ Surface material } & Plastic & Referent & & 0.776 \\
\hline & Cork & $0.49^{\mathrm{a}}$ & 0.346 & \\
\hline & Fabric & 0.61 & 0.999 & \\
\hline & Laminate & 0.57 & 0.693 & \\
\hline \multirow[t]{6}{*}{ Surface sampled } & End of bed & Referent & & 0.111 \\
\hline & Bulletin board & $1.18^{\mathrm{a}}$ & 0.999 & \\
\hline & Chair back & 4.39 & 0.200 & \\
\hline & Overbed table & 1.03 & 0.999 & \\
\hline & Privacy curtain & 1.08 & 0.999 & \\
\hline & Television & $1.15^{\mathrm{a}}$ & 0.999 & \\
\hline \multicolumn{5}{|l|}{$\begin{array}{c}\text { Dependent } \\
\text { variable: surface } \\
\text { contaminated } \\
\text { with C. difficile }\end{array}$} \\
\hline \multirow[t]{3}{*}{ Ward } & Medicine A & Referent & & 0.884 \\
\hline & Medicine B & 0.76 & 0.744 & \\
\hline & Surgery & 0.73 & 0.758 & \\
\hline \multirow{3}{*}{$\begin{array}{c}\text { Type of } \\
\text { patient room }\end{array}$} & Unexposed & Referent & & 0.008 \\
\hline & MRSA exposed & 0.31 & 0.301 & \\
\hline & C. difficile exposed & 4.71 & 0.031 & \\
\hline \multirow[t]{4}{*}{ Surface material } & Plastic & Referent & & 0.017 \\
\hline & Cork & 3.84 & 0.030 & \\
\hline & Fabric & 0.36 & 0.336 & \\
\hline & Laminate & 0.97 & 0.999 & \\
\hline \multirow[t]{6}{*}{ Surface sampled } & End of bed & Referent & & 0.059 \\
\hline & Bulletin board & 4.03 & 0.131 & \\
\hline & Chair back & 1.03 & 0.999 & \\
\hline & Overbed table & 1.03 & 0.999 & \\
\hline & Privacy curtain & $0.44^{\mathrm{a}}$ & 0.494 & \\
\hline & Television & 1.15 & 0.999 & \\
\hline
\end{tabular}

$\mathrm{OR}=$ odds ratio

a Median unbiased estimates. 
Table 5 Descriptive statistics of variables for MRSA and $C$. difficile contamination in the ward environment

\begin{tabular}{lcc}
\hline Variables $^{\text {a }}$ & MRSA & C. difficile \\
\hline Ward: & & \\
Medicine $A(n=72)$ & $5.6 \%(4)$ & $8.3 \%(6)$ \\
Medicine $B(n=67)$ & $1.5 \%(1)$ & $4.5 \%(3)$ \\
Surgery $(n=97)$ & $1.0 \%(1)$ & $5.2 \%(5)$ \\
Surface location: & & \\
Nurses' and physician work areas $(n=99)$ & $1.0 \%(1)$ & $6.1 \%(6)$ \\
Hallway $(n=109)$ & $3.7 \%(4)$ & $5.5 \%(6)$ \\
Visiting room $(n=28)$ & $3.6 \%(1)$ & $7.1 \%(2)$ \\
Surface material: & & \\
Fabric $(n=78)$ & $2.6 \%(2)$ & $6.4 \%(5)$ \\
Laminate $(n=15)$ & $13.3 \%(2)$ & $0 \%(0)$ \\
Plastic $(n=103)$ & $1.9 \%(2)$ & $6.8 \%(7)$ \\
Rubber $(n=17)$ & $0 \%(0)$ & $5.9 \%(1)$ \\
Wood $(n=23)$ & $0 \%(0)$ & $4.3 \%(1)$ \\
Surface sampled: & & \\
Chair $(n=55)$ & $0 \%(0)$ & $5.9 \%(1)$ \\
Clean linen $(n=15)$ & $0 \%(0)$ & $17.6 \%(3)$ \\
Clean towels $(n=16)$ & $0 \%(0)$ & $0 \%(0)$ \\
Computer keyboard $(n=55)$ & & \\
Counter top $(n=15)$ & $0 \%(0)$ & $6.7 \%(1)$ \\
Drug cart $(n=17)$ & $0 \%(0)$ & $0 \%(0)$ \\
Glove box holder $(n=13)$ & $1.8 \%(1)$ & $5.5 \%(3)$ \\
Hand rail $(n=17)$ & $13.3 \%(2)$ & $0 \%(0)$ \\
Heating oven handle $(n=17)$ & $5.9 \%(1)$ \\
Patient chart $(n=16)$ & $7.7 \%(1)$ \\
\hline$n=n u m b e r$ \\
\hline
\end{tabular}

$\mathrm{n}=$ number of samples.

${ }^{a}$ Denominator is based on the number of surfaces in the general ward environment that were tested.

surfaces for MRSA or C. difficile contamination based on the univariable analyses (Table 6).

The distribution of MRSA and C. difficile contamination, per visit, fluctuated during the study period (Figure 1). For visits 5 and 6, MRSA was not recovered from the general ward environment. The highest prevalence of $C$. difficile contamination occurred during visit 4 . Compared to the time period prior to the hospital outbreaks, there was no statistically significant increase in the odds of contamination with MRSA (OR 0.19; $\mathrm{P}=0.213$ ) or $C$. difficile (OR 1.02; $\mathrm{P}=0.999$ ) in the time period following the outbreaks.

Two different spa types were identified among the six MRSA isolates collected from the general ward environment (Table 2). One isolate was identified containing the PVL toxin gene and corresponded to CMRSA-10. For $C$. difficile, eight different ribotypes were identified among the 14 isolates (Table 3), including ribotypes $027(\mathrm{n}=2)$ and $078(\mathrm{n}=5)$.
Only one surface was positive for MRSA and C. difficile on the same visit; a chair located in a nursing station on medicine ward B. Heating oven handles located in medicine ward A were contaminated with $C$. difficile on two separate visits. Molecular characterization of these C. difficile isolates revealed ribotypes 027 and 078 .

\section{Patient isolates}

Data pertaining to MRSA and C. difficile isolates from patients are presented in Tables 2 and 3, respectively. For MRSA, a total of 46 patient isolates were collected, representing nine different spa types, with spa type 2/ t002 being the most prevalent. In one MRSA exposed room, the privacy curtain was contaminated with the same MRSA spa type that was identified in the patient, spa type 2/t002. Two patients were identified with MRSA spa type $1 / \mathrm{t} 008$ during the study period. However, only one of these patients was present in the ward when a chair located in the visiting room on the same ward as the patient was identified as being contaminated with MRSA spa type $1 / \mathrm{t} 008$. Although six patients were identified with MRSA spa type 437/t003, none of these patients were present in the surgical ward when a chair located in an unexposed room was found to be contaminated with spa type 437/t003. Despite nine different MRSA spa types identified in the patient population, six of these spa types were not detected on surfaces located in patient rooms or the ward environment.

For C. difficile, 22 patient specimens were collected during the study period; however, $C$. difficile could not be isolated from one patient specimen. For 21 C. difficile isolates, 11 ribotypes were identified, with ribotype 027 being the most prevalent in the patient population. During visit 4 , ribotype 078 was identified from the majority of $C$. difficile contaminated surfaces located in patient rooms and the general environment. However, only one C. difficile patient was identified with ribotype 078 during the study period. Although this patient was admitted to the surgical ward shortly after visit 3 , this patient was not present in the hospital during visit 4. Ribotype $\mathrm{MOH}$ $\mathrm{V}$ was identified from one patient specimen; however, this patient was not present in the medicine or surgical wards when $\mathrm{MOH}-\mathrm{V}$ was identified in an unexposed room and the ward environment. A total of seven $C$. difficile patients were identified with ribotype 027 during the study period. However none of these patients were admitted to the medicine ward where ribotype 027 was found in an unexposed room and the ward environment. A total of eight ribotypes identified from patient specimens were not recovered from the hospital environment.

\section{Discussion}

To our knowledge, this is the first study to explore MRSA and C. difficile contamination, concurrently, in 
Table 6 Univariable regression analyses of variables associated with MRSA or C. difficile contamination in the ward environment

\begin{tabular}{|c|c|c|c|c|}
\hline Variable & Description & OR & P-value & $\begin{array}{l}\text { Overall } \\
\text { P-value for } \\
\text { the variable }\end{array}$ \\
\hline \multicolumn{5}{|l|}{$\begin{array}{l}\text { Dependent } \\
\text { variable: surface } \\
\text { contaminated } \\
\text { with MRSA }\end{array}$} \\
\hline \multirow[t]{6}{*}{ Visit } & 1 & Referent & & 0.390 \\
\hline & 2 & 0.42 & 0.628 & \\
\hline & 3 & 0.35 & 0.617 & \\
\hline & 4 & 0.31 & 0.361 & \\
\hline & 5 & $0.26^{\mathrm{a}}$ & 0.242 & \\
\hline & 6 & $0.37^{\mathrm{a}}$ & 0.267 & \\
\hline \multirow[t]{3}{*}{ Ward } & Medicine A & Referent & & 0.185 \\
\hline & Medicine B & 0.26 & 0.368 & \\
\hline & Surgery & 0.18 & 0.165 & \\
\hline \multirow[t]{5}{*}{ Surface material } & Plastic & Referent & & 0.099 \\
\hline & Fabric & 1.33 & 0.999 & \\
\hline & Laminate & 7.53 & 0.078 & \\
\hline & Rubber & $2.51^{\mathrm{a}}$ & 0.999 & \\
\hline & Wood & $1.85^{\mathrm{a}}$ & 0.999 & \\
\hline \multirow[t]{3}{*}{ Location } & Hallway & Referent & & 0.492 \\
\hline & Visiting Room & 0.97 & 0.999 & \\
\hline & Work area & 0.27 & 0.372 & \\
\hline \multirow[t]{7}{*}{ Surface sampled } & $\begin{array}{l}\text { Computer } \\
\text { keyboard }\end{array}$ & Referent & & 0.176 \\
\hline & Chair & 2.03 & 0.999 & \\
\hline & Clean towels & 1.77 & 0.999 & \\
\hline & Counter top & 7.96 & 0.114 & \\
\hline & Drug cart & $3.24^{\mathrm{a}}$ & 0.999 & \\
\hline & $\begin{array}{l}\text { Heating oven } \\
\text { handles }\end{array}$ & $3.24^{\mathrm{a}}$ & 0.999 & \\
\hline & Other $^{\mathrm{b}}$ & 1.19 & 0.999 & \\
\hline \multicolumn{5}{|l|}{$\begin{array}{l}\text { Dependent } \\
\text { variable: surface } \\
\text { contaminated } \\
\text { with C. difficile }\end{array}$} \\
\hline \multirow[t]{6}{*}{ Visit } & 1 & Referent & & 0.439 \\
\hline & 2 & 0.31 & 0.380 & \\
\hline & 3 & 0.52 & 0.677 & \\
\hline & 4 & 1.25 & 0.999 & \\
\hline & 5 & 0.25 & 0.361 & \\
\hline & 6 & 0.35 & 0.404 & \\
\hline \multirow[t]{3}{*}{ Ward } & Medicine A & Referent & & 0.609 \\
\hline & Medicine B & 0.52 & 0.496 & \\
\hline & Surgery & 0.59 & 0.531 & \\
\hline
\end{tabular}

Table 6 Univariable regression analyses of variables associated with MRSA or C. difficile contamination in the ward environment (Continued)

\begin{tabular}{|c|c|c|c|c|}
\hline \multirow[t]{5}{*}{ Surface material } & Plastic & Referent & & 0.936 \\
\hline & Fabric & 0.94 & 0.999 & \\
\hline & Laminate & $0.69^{a}$ & 0.593 & \\
\hline & Rubber & 0.86 & 0.999 & \\
\hline & Wood & 0.63 & 0.999 & \\
\hline \multirow[t]{3}{*}{ Location } & Hallway & Referent & & 0.999 \\
\hline & Visiting Room & 1.32 & 0.999 & \\
\hline & Work area & 1.11 & 0.999 & \\
\hline \multirow[t]{7}{*}{ Surface sampled } & $\begin{array}{l}\text { Computer } \\
\text { keyboard }\end{array}$ & Referent & & 0.434 \\
\hline & Chair & 1.36 & 0.999 & \\
\hline & Clean towels & 0.58 & 0.999 & \\
\hline & Counter top & $0.93^{\mathrm{a}}$ & 0.593 & \\
\hline & Drug cart & 1.08 & 0.999 & \\
\hline & $\begin{array}{l}\text { Heating oven } \\
\text { handles }\end{array}$ & 3.63 & 0.139 & \\
\hline & Other $^{b}$ & 0.79 & 0.999 & \\
\hline
\end{tabular}

both patient rooms and the ward environment of a community hospital, longitudinally. The percentages of exposed patient rooms that were found to be contaminated with MRSA or $C$. difficile were lower compared to other studies [24-27]. This contrast in results may have been attributed to the number of patient rooms and surfaces investigated in addition to different sampling and culturing methodologies used among the studies.

Surfaces located in rooms with a $C$. difficile patient had increased odds of being contaminated with $C$. difficile compared to unexposed and MRSA exposed rooms, an unsurprising result given the potential for infected patients to contaminate their environment and the ability of $C$. difficile spores to survive in the hospital environment for months [8]. Interestingly, unexposed rooms were also identified as having a large number of surfaces contaminated with MRSA or $C$. difficile. Previous studies have also reported the presence of these HA pathogens on surfaces located in patient areas not occupied by MRSA or C. difficile patients $[25,27,28]$. Reasons for the extensive contamination of surfaces in unexposed patient rooms may include transfer of pathogens via hands or fomites of staff, patients, and visitors; misclassification of patient rooms due to unidentified colonization status of individuals; or failure of routine cleaning and disinfection practices. Although MRSA and $C$. difficile are susceptible to the disinfectants used in this facility, a quaternary ammonium compound and bleach, respectively, inadequate cleaning and disinfection practices cannot be 


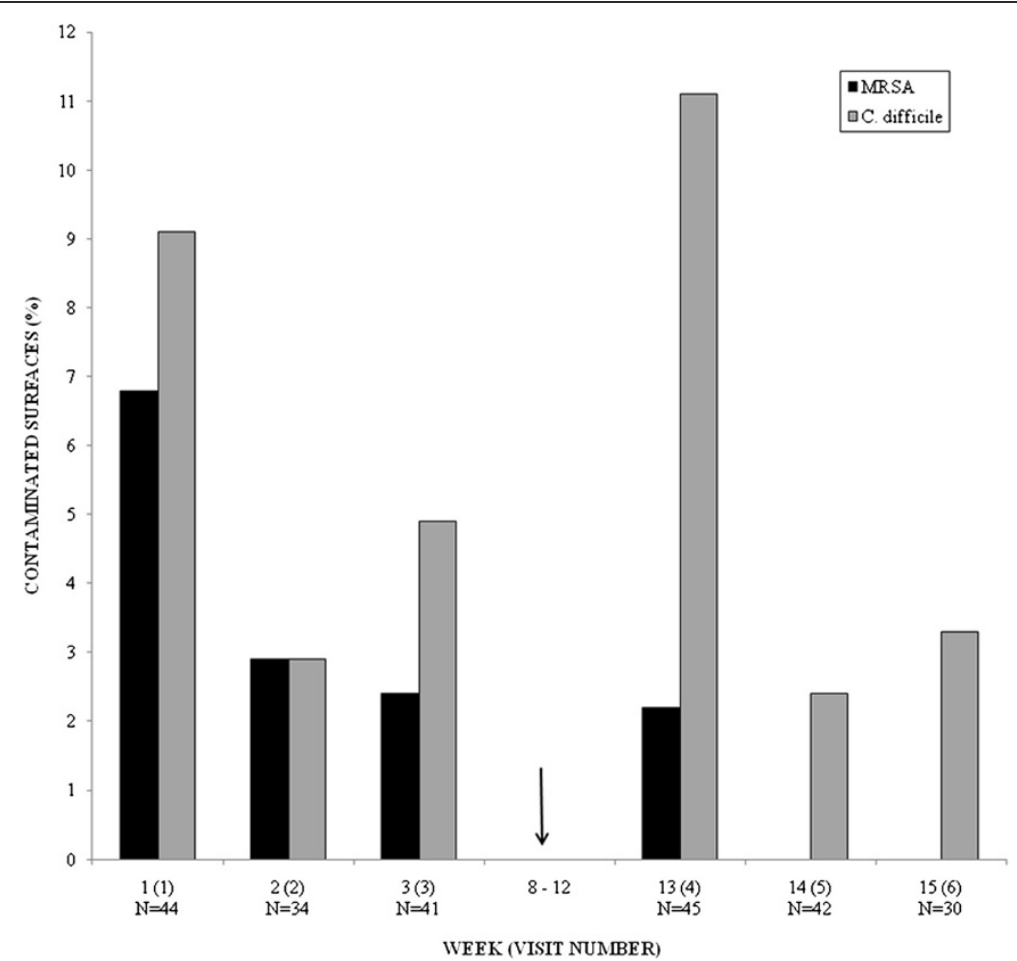

Figure 1 Distribution of MRSA and C. difficile contamination in the ward environment by week and visit. The arrow indicates when an MRSA outbreak (weeks 8-13) and an influenza outbreak (weeks 9-11) occurred in the hospital. $N=$ number of surfaces sampled.

excluded. In a multicentre study conducted by Carling and colleagues [29], only 49.5\% (1748/3532) of high touch surfaces located in intensive care units were identified as being clean following terminal cleaning practices. Lastly, rooms housing known MRSA or C. difficile-infected individuals have enhanced cleaning protocols compared to other rooms, as a result, surfaces may not be cleaned as rigorously or as often in unexposed rooms. These data highlight the need for regular and proper cleaning of all hospital areas, not just those known to house patients with pathogens such as MRSA and C. difficile.

In patient rooms, the identification of MRSA or C. difficile on overbed tables, privacy curtains, and televisions is consistent with the literature [24,30-36], and presumably, any hand contact surface is at some degree of risk for contamination. While understanding higher risk sites is important, these data indicate the need for broad cleaning and disinfection, including surfaces that often receive less attention. In the present investigation, chairs and bulletin boards were sampled in patient rooms as it was noted that staff, patients, and visitors would move chairs by grasping the top surface of the chair back. Subsequently, MRSA and $C$. difficile were cultured from this surface with all positive chair backs specifically located in unexposed patient rooms. In unexposed and exposed patient rooms, bulletin boards were negative for MRSA but positive for $C$. difficile. Upon further investigation it was determined that in rooms with a patient under isolation precautions, tourniquets used for phlebotomies were secured to the bulletin boards. As $C$. difficile has been cultured from the skin of asymptomatic patients [37] and from the skin of patients with CDI $[37,38]$, it is theorized that the tourniquets became contaminated with $C$. difficile which subsequently contaminated the bulletin board. Although results from the univariable analyses indicated that bulletin boards, compared to the end of the patient bed, were not significantly associated with $C$. difficile contamination, cork surfaces, compared to plastic and fabric surfaces, had significantly increased odds of being contaminated with $C$. difficile. In this investigation all bulletin boards in patient rooms were made of cork, a porous material with an irregular surface. Due to the surface characteristics of cork, which make this material difficult to clean and disinfect, and the likelihood that bulletin boards were rarely, if ever disinfected, it is possible that bulletin boards may have acted as a source of $C$. difficile dissemination in patient rooms. It is not clear why MRSA was not recovered from any of the bulletin boards in this investigation since phlebotomy tourniquets have also been documented as acting as a reservoir for MRSA [39].

Overall, $2.5 \%$ and $5.9 \%$ of surfaces in the ward environment were contaminated with MRSA or C. difficile, respectively. However, in the literature, the prevalence of 
MRSA and C. difficile contamination of the general hospital environment is extremely variable $[4,28,40-44]$ and therefore difficult to compare results between studies. These differences in prevalence may be attributed to different study designs as well as the presence and number of MRSA and $C$. difficile patients during the study period.

In the general ward environment, surfaces covered in fabric, laminate, or plastic had the highest level of MRSA or $C$. difficile contamination; however there was no statistically significant association between type of material and contamination. As these materials can vary widely in their texture, they can pose a substantial problem with respect to cleaning and disinfection, and therefore act as potential sources of MRSA and C. difficile transmission and dissemination. Staphylococcus aureus is able to survive adverse environmental conditions and persist in the hospital environment [45] including surviving in hospital dust for nearly a year [7]. Experiments conducted using swatches of fabric and plastic have demonstrated that staphylococci can survive days to months after drying on these types of materials which are commonly found in the hospital environment [46]. In addition, $C$. difficile spores are highly resistant to environmental effects and many commonly used disinfectants $[47,48]$, which can result in their survival for months to years in the hospital environment, unless physically removed or exposed to an adequate disinfectant [8].

In the ward environment, countertops, heating oven handles, computer keyboards, and chairs had the highest prevalence of MRSA or C. difficile contamination; however, there was no statistically significant association between specific surfaces and contamination with either pathogen. This lack of statistical association is in contrast to an earlier study investigating contamination in the ward environment of three hospitals in which chairs, hand rails, isolation carts, and sofas had significantly greater odds for MRSA contamination compared to computer keyboards [40]. However, in that particular study, the prevalence of MRSA contamination was considerably higher $(11.8 \%)$ and the low prevalence of $C$. difficile contamination (2.4\%) did not allow for statistical model construction. Nonetheless, results from the present investigation demonstrate that contaminated surfaces are common hand-touch sites that are frequently touched by staff and/or patients and visitors. Therefore, contamination may be attributed to lack of hand hygiene, hand hygiene practices that are ineffective at eliminating $C$. difficile spores, and/or inconsistent cleaning and disinfection protocols.

During visits 3-6, C. difficile was identified as the predominant pathogen contaminating the ward environment. Although MRSA patients were present in the medical and surgical wards for all six visits, $C$. difficile patients were only present in the wards for visits 4-6. For visit 4 (week 13), the prevalence of MRSA was relatively small despite an MRSA outbreak during weeks 813; however there was no significant association between the prevalence of MRSA contamination prior to, and following, the outbreak. As the MRSA outbreak occurred on a ward not involved in this investigation, the substantial decrease of MRSA in the ward environment may have been a result of overall increase in hand hygiene and restricting patient movement and visitors to prevent the outbreak spreading to other wards. Furthermore, an influenza outbreak, which also occurred in a ward not participating in this investigation, was declared during weeks $9-11$ of the study period. Following this outbreak, the prevalence of $C$. difficile contamination in the ward environment of the medical and surgical wards fluctuated over the last three visits with a substantially higher prevalence observed on visit 4; however, there was no significant association between the prevalence of $C$. difficile contamination before and after the outbreak. This increase in $C$. difficile contamination in the environment during the latter part of this investigation may have been attributed to the presence of $C$. difficile patients in the study wards. However, research has demonstrated an association between the presence of the influenza virus and an increase in the incidence rate of CDI in hospitalised patients during the winter months $[49,50]$. Possible factors contributing to this association include antimicrobial use $[49,50]$ and reductions in cleaning and disinfection of non-outbreak wards because of increased efforts directed towards outbreak wards. In the present investigation, the monthly CDI incidence rate increased from 0.73 to 0.83 cases $/ 1,000$ patient days following the influenza outbreak. It is possible that patients with $C$. difficile were not identified and isolated, or a focus on influenza outbreak management led to decreased infection control activities directed against $C$. difficile, subsequently resulting in an increase in $C$. difficile contamination of the general environment.

The predominance of spa types corresponding to CMRSA-2, a sequence type 5 (ST5) clone, also known as USA100, was not unexpected since it is the leading cause of HA-MRSA in Canada [1,51]. The distribution of MRSA strains in patient rooms, general ward areas, and patients was similar, albeit with more apparent strain diversity among patients than in the environment. It is unclear whether this indicates that CMRSA-2 is more adapted for surviving in the environment, as strain-dependent environmental persistence has not been investigated.

In total, 16 different toxigenic $C$. difficile ribotypes were identified. Ribotype 027 was predominant in the patient population and was the second most prevalent ribotype identified contaminating the ward environment. 
This specific ribotype is responsible for various outbreaks of CDI with increased severity, high relapse rates, and significant mortality [52,53]. Despite its association with outbreaks, this ribotype is also common in endemic disease and was the second most prevalent strain in a study of $C$. difficile isolates from Ontario diagnostic laboratories [54]. This is further evidence that while this strain is of particular concern, ribotype 027 can be present in patients and the environment in the absence of a CDI outbreak. Yet, overall, $C$. difficile typing data indicate less of a relationship between patient and environmental strains than with MRSA. In particular, ribotype 078 accounted for $64 \%$ of isolates from patient rooms and $36 \%$ from the ward environment but was identified in only one patient. Increases in the incidence of CDI caused by this particular strain have been reported internationally [55], including in Canada where 078 increased from $0.5 \%$ of CDI isolates in 2004/2005 to $1.6 \%$ in 2008 [56]. The reason for the high prevalence of 078 in the environment of this healthcare facility and the discordance between environmental and patient prevalence is not known. However, this particular ribotype is prevalent among $C$. difficile strains isolated from food animals in Canada [57-59] and was commonly identified in a study of Ontario household environments [60]. The participating hospital serves a rural community, which may increase the likelihood for exposure to 078 in the community, with subsequent transmission into the hospital. While ribotype 078 is referred to as a hypervirulent strain, it is not likely as pathogenic or transmissible as ribotype 027 , based on fewer reports of severe disease or outbreaks associated with 078. Therefore, it is plausible that environmental contamination could occur more readily than patient disease if ribotype 078 is more common in people in the community but less able to cause disease, in comparison to ribotype 027. Given the lack of surveillance data involving non-diarrheic individuals, it is difficult to substantiate these hypotheses and more information is required regarding the epidemiology of this potentially emerging strain and the potential role of non-CDI patients, visitors, and staff in the contamination of the hospital environment.

The prevalence of toxinotype variants (toxinotypes other than toxinotype 0) in patients was striking, with only $14 \%$ of isolates belonging to toxinotype 0 . The high prevalence and diversity of toxinotype variants seen in our study hospital have not been reported previously in a patient population and is in contrast with an earlier multicentre study in the province where ribotype 001, a toxinotype 0 strain, was most common (25.5\%) [54]. Similarly, the high prevalence of patient strains possessing the binary toxin strain (81\%) was remarkably high. This toxin is most commonly found in hypervirulent strains, although it is not clear whether it is an important virulence factor or simply just commonly present in strains that are more virulent.

This study has several limitations. For $C$. difficile, several ribotypes present in the hospital environment were not identified from patient specimens. This discordance may have been attributed to isolates not being collected or patients with $C$. difficile not being identified because of a lack of routine screening or the use of a diagnostic test with moderate sensitivity $[61,62]$. In addition, not all surfaces were sampled each visit since some surfaces were cleaned just prior to our arrival for sampling. Lastly, the number of MRSA and $C$. difficile exposed rooms available for sampling was limited, which may have resulted in a lack of power to identify significant risk factors associated with surfaces being contaminated with MRSA or C. difficile.

\section{Conclusions}

In conclusion, the results from this investigation offer detailed information on MRSA and $C$. difficile contamination in the hospital environment. The identification of specific surfaces, materials, and locations as having an increased prevalence of MRSA and C. difficile contamination can be used by hospital personnel for surveillance purposes to assess and implement effective control measures for reducing the transmission of MRSA and C. difficile within the healthcare setting. In addition, this study demonstrates the variety of MRSA and $C$. difficile strains that can be found in patient populations and the hospital environment. Further research investigating the persistence of specific MRSA and $C$. difficile strains in the hospital environment may be warranted.

\section{Abbreviations}

MRSA: Meticillin-resistant Staphylococcus aureus; CMRSA: Canadian epidemic meticillin-resistant Staphylococcus aureus; CDI: Clostridium difficile infection; HA: Healthcare-associated; CA: Community-associated; PVL: Panton-Valentine leukocidin; $t c d A$ : Toxin A; $t c d B$ : Toxin B; $c d t A$ : Binary toxin; ST: Sequence type; OR: Odds ratio; N: Number.

\section{Competing interests}

The authors declare that they have no competing interests.

\section{Authors' contributions}

MCF contributed to study design, data collection, analysis, and drafting of the manuscript. DLP and OB contributed to study design and statistical analysis. JSW contributed to study design and molecular analysis. RRS contributed to study design. All authors contributed to the editing and final version of the manuscript.

\section{Acknowledgements}

The authors wish to thank the hospital that participated in this study, the Infection Prevention and Control Department personnel for research assistance, and the microbiology laboratory personnel for collecting patient specimens. We would also like to thank Joyce Rousseau for laboratory support. The statistical infrastructure for analyses was supported through a grant to D.L. Pearl from the Canada Foundation for Innovation and the Ontario Research Fund. 


\section{Author details}

'Department of Population Medicine, University of Guelph, Guelph, ON, Canada. 'Department of Mathematics and Statistics, University of Guelph, Guelph, ON, Canada. ${ }^{3}$ Department of Pathobiology, University of Guelph, Guelph, ON, Canada.

Received: 18 April 2013 Accepted: 18 July 2013

Published: 24 July 2013

\section{References}

1. Simor AE, Gilbert NL, Gravel D, Mulvey MR, Bryce E, Loeb M, Matlow A, McGeer A, Louie L, Campbell J, Canadian Nosocomial Infection Surveillance Program: Methicillin-resistant Staphylococcus aureus colonization or infection in Canada: national surveillance and changing epidemiology, 1995-2007. Infect Control Hosp Epidemiol 2010, 31:348-356.

2. Gravel D, Miller M, Simor A, Taylor G, Gardam M, McGeer A, Hutchinson J, Moore D, Kelly S, Boyd D, Mulvey M, Canadian Nosocomial Infection Surveillance Program: Health care-associated Clostridium difficile infection in adults admitted to acute care hospitals in Canada: a Canadian nosocomial infection surveillance program study. Clin Infect Dis 2009, 48:568-576.

3. Poutanen SM, Simor AE: Clostridium difficile-associated diarrhea in adults. CMAJ 2004, 171:51-58

4. Dancer SJ, White LF, Lamb J, Girvan EK, Robertson C: Measuring the effect of enhanced cleaning in a UK hospital: a prospective cross-over study. BMC Med 2009, 7:28.

5. Boyce JM, Havill NL, Otter JA, McDonald LC, Adams NM, Cooper T, Thompson A, Wiggs L, Killgore G, Tauman A, Noble-Wang J: Impact of hydrogen peroxide vapour room decontamination on Clostridium difficile environmental contamination and transmission in a health care setting. Infect Control Hosp Epidemiol 2008, 29:723-729.

6. Boyce JM: Environmental contamination makes an important contribution to hospital infection. J Hosp Infect 2007, 65(Suppl 2):50-54.

7. Wagenvoort JH, Sluijsmans W, Penders RJ: Better environmental survival of outbreak vs. sporadic MRSA isolates. J Hosp Infect 2000, 45:231-234.

8. Mutters R, Nonnenmacher C, Susin C, Albrecht U, Kropatsch R, Schumacher S: Quantitative detection of Clostridium difficile in hospital environmental samples by real-time polymerase chain reaction. J Hosp Infect 2009, 7:43-48.

9. Dettenkofer M, Ammon A, Astagneau P, Dancer SJ, Gastmeier P, Harbarth S, Humphreys H, Kern W, Lyytikäinen O, Sax H, Voss A, Widmer AF: Infection control-a European research perspective for the next decade. J Hosp Infect 2011, 77:7-10.

10. Samore MH: Epidemiology of nosocomial Clostridium difficile. J Hosp Infect 1999, 43(Suppl):183-190.

11. Annex A: Screening, testing and surveillance for antibiotic-resistant organisms (AROs). http://www.publichealthontario.ca/en/eRepository/ PIDAC-IPC_Annex_A_Screening_Testing_Surveillance_AROs_2013.pdf.

12. Shopsin B, Gomez M, Montgomery SO, Smith DH, Waddington M, Dodge DE, Bost DA, Riehman M, Naidich S, Kreiswirth BN: Evaluation of protein A gene polymorphic region DNA sequencing for typing Staphylococcus aureus strains. I Clin Microbiol 1999, 37:3556-3563.

13. eGenomics. http://tools.egenomics.com.

14. Ridom SpaServer. http://www.spaserver.ridom.de.

15. Golding GR, Campbell JL, Spreitzer DJ, Veyhl J, Surynicz K, Simor A, Mulvey MR, Canadian Nosocomial Infection Surveillance Program: A preliminary guideline for the assignment of methicillin-resistant Staphylococcus aureus to a Canadian pulsed-field gel electrophoresis epidemic type using spa typing. Can J Infect Dis Med Microbiol 2008, 19:273-281.

16. Rankin S, Roberts S, O'Shea K, Maloney D, Lorenzo M, Benson CE: Panton valentine leukocidin (PVL) toxin positive MRSA strains isolated from companion animals. Vet Microbiol 2005, 108:145-148.

17. Kato H, Kato N, Watanabe K, Iwai N, Nakamura H, Yamamoto T, Suzuki K, Kim SM, Chong Y, Wasito EB: Identification of toxin A-negative, toxin B-positive Clostridium difficile by PCR. J Clin Microbiol 1998, 36:2178-2182.

18. Lemee L, Dhalluin A, Testelin S, Mattrat MA, Maillard K, Lemeland JF, Pons $J$ : Multiplex PCR targeting tpi (triose phosphate isomerise), tcdA (toxin a), $t c d B$ (toxin $B$ ), genes for toxigenic culture of Clostridium difficile. J Clin Microbiol 2004, 42:5710-5714.

19. Stubbs S, Rupnik M, Gibert M, Brazier J, Duerden B, Popoff M: Production of actin-specific ADP-ribosyltransferase (binary toxin) by strains of Clostridium difficile. FEMS Microbiol Lett 2000, 186:307-312
20. Bidet $P$, Barbut $F$, Lalande $V$, Burghoffer B, Petit JC: Development of a new PCR-ribotyping method for Clostridium difficile based on ribosomal RNA gene sequencing. FEMS Microbiol Lett 1999, 175:261-266.

21. Rupnik M, Avesani V, Janc M, von Eichel-Streiber C, Delmée M: A nove toxinotyping scheme and correlation of toxinotypes with serogroups of Clostridium difficile isolates. J Clin Microbiol 1998, 36:2240-2247.

22. Dohoo IR, Martin W, Stryhn H: Model-building strategies, Veterinary epidemiologic research. Charlottetown, Prince Edward Island: AVC, Inc; 2003:317-334.

23. StataCorp: Exlogistic - exact logistic regression, Stata statistical software: release 10. College Station, Texas: Stata Press; 2007:423-439.

24. Rohr U, Kaminski A, Wilhelm M, Jurzik L, Gatermann S, Muhr G: Colonization of patients and contamination of the patients' environment by MRSA under conditions of single-room isolation. Int J Hyg Environ Health 2009, 212:209-215.

25. French GL, Otter JA, Shannon KP, Adams NM, Watling D, Parks MJ: Tackling contamination of the hospital environment by methicillin-resistant Staphylococcus aureus (MRSA): a comparison between conventional terminal cleaning and hydrogen peroxide vapour decontamination. J Hosp Infect 2004, 57:31-37.

26. Eckstein BC, Adams DA, Eckstein EC, Rao A, Sethi AK, Yadavalli GK, Donskey $\mathrm{CJ}$ : Reduction of Clostridium difficile and vancomycin-resistant Enterococcus contamination of environmental surfaces after an intervention to improve cleaning methods. BMC Infect Dis 2007, 7:61.

27. Dubberke ER, Reske KA, Noble-Wang J, Thompson A, Killgore G, Mayfield J, Camins B, Woeltje K, McDonald JR, McDonald LC, Fraser VJ: Prevalence of Clostridium difficile environmental contamination and strain variability in multiple health care facilities. Am J Infect Control 2007, 35:315-318.

28. Dumford DM 3rd, Nerandzic MM, Eckstein BC, Donskey CJ: What is on that keyboard? Detecting hidden environmental reservoirs of Clostridium difficile during an outbreak associated with North American pulsed-field gel electrophoresis type 1 strains. Am J Infect Control 2009, 37:15-19.

29. Carling PC, Parry MF, Bruno-Murtha LA, Dick B: Improving environmental hygiene in 27 intensive care units to decrease multidrug-resistant bacterial transmission. Crit Care Med 2010, 38:1054-1059.

30. Chang S, Sethi AK, Eckstein BC, Stiefel U, Cadnum JL, Donskey CJ: Skin and environmental contamination with methicillin-resistant Staphylococcus aureus among carriers identified clinically versus through active surveillance. Clin Infect Dis 2009, 15:1423-1428.

31. Sexton T, Clarke P, O'Neill E, Dillane T, Humphreys H: Environmental reservoirs of methicillin-resistant Staphylococcus aureus in isolation rooms: correlation with patient isolates and implications for hospital hygiene. J Hosp Infect 2006, 62:187-194.

32. Rampling A, Wiseman S, Davis L, Hyett AP, Walbridge AN, Payne GC, Cornaby AJ: Evidence that hospital hygiene is important in the control of methicillin-resistant Staphylococcus aureus. J Hosp Infect 2001, 49:109-116.

33. Verity P, Wilcox MH, Fawley W, Parnell P: Prospective evaluation of environmental contamination by Clostridium difficile in isolation side rooms. J Hosp Infect 2001, 49:204-209.

34. Boyce JM, Potter-Bynoe G, Chenevert C, King T: Environmental contamination due to methicillin-resistant Staphylococcus aureus: possible infection control implications. Infect Control Hosp Epidemiol 1997, 18:622-627.

35. Trillis F 3rd, Eckstein EC, Budavich R, Pultz MJ, Donskey CJ: Contamination of hospital curtains with health care-associated pathogens. Infect Control Hosp Epidemiol 2008, 29:1074-1076

36. Stacey A, Burden P, Croton C, Jones E: Contamination of television sets by methicillin-resistant Staphylococcus aureus (MRSA). J Hosp Infect 1998, 39:243-244.

37. Dumford DM 3rd, Nerandzic M, Chang S, Richmond MA, Donskey C: Epidemiology of Clostridium difficile and vancomycin-resistant Enterococcus colonization in patients on a spinal cord unit. J Spinal Cord Med 2011, 34:22-27.

38. Sethi AK, Al-Nassir WN, Nerandzic MM, Bobulsky GS, Donskey CJ: Persistence of skin contamination and environmental shedding of Clostridium difficile during and after treatment of $C$. difficile infection. Infect Control Hosp Epidemiol 2010, 31:21-27.

39. Leitch A, McCormick I, Gunn I, Gillespie T: Reducing the potential for phlebotomy tourniquets to act as a reservoir for methicillin-resistant Staphylococcus aureus. J Hosp Infect 2006, 63:428-431.

40. Faires MC, Pearl DL, Ciccotelli WA, Straus K, Zinken G, Berke O, Reid-Smith $\mathrm{RJ}$, Weese JS: A prospective study to examine the epidemiology of 
methicillin-resistant Staphylococcus aureus and Clostridium difficile contamination in the general environment of three community hospitals in southern Ontario, Canada. BMC Infect Dis 2012, 12:290.

41. Shelly MJ, Scanlon TG, Ruddy R, Hannan MM, Murray JG: Meticillin-resistant Staphylococcus aureus (MRSA) environmental contamination in a radiology department. Clin Radiol 2011, 66:861-864.

42. Martirosian G: Recovery of Clostridium difficile from hospital environments. J Clin Microbiol 2006, 44:1202-1203.

43. Pulvirenti JJ, Gerding DN, Nathan C, Hafiz I, Mehra T, Marsh D, Kocka F, Rice $T$, Fischer SA, Segreti J, Weinstein RA: Difference in the incidence of Clostridium difficile among patients infected with human immunodeficiency virus admitted to a public and a private hospital. Infect Control Hosp Epidemiol 2002, 23:641-647.

44. Bures S, Fishbain JT, Uyehara CF, Parker JM, Berg BW: Computer keyboards and faucet handles as reservoirs of nosocomial pathogens in the intensive care unit. Am J Infect Control 2000, 28:465-471.

45. Conly JM, Johnston BL: The emergence of methicillin-resistant Staphylococcus aureus as a community-acquired pathogen in Canada. Can J Infect Dis 2003, 14:249-251.

46. Neely AN, Maley MP: Survival of enterococci and staphylococci on hospital fabrics and plastic. I Clin Microbiol 2000, 38:724-726.

47. Fawley WN, Wilcox MH: Molecular epidemiology of endemic Clostridium difficile infection. Epidemiol Infect 2001, 126:343-350

48. Kim KH, Fekety R, Batts DH, Brown D, Cudmore M, Silva J Jr, Waters D: Isolation of Clostridium difficile from the environment and contacts of patients with antibiotic-associated colitis. J Infect Dis 1981, 143:42-50.

49. Gilca R, Fortin E, Frenette C, Longtin Y, Gourdeau M: Seasonal variations in Clostridium difficile infections are associated with influenza and respiratory syncytial virus activity independently of antibiotic prescriptions: a time-series analysis in Quebec, Canada. Antimicrob Agents Chemother 2012, 56:639-646.

50. Polgreen PM, Yang M, Bohnett LC, Cavanaugh JE: A time-series analysis of Clostridium difficile and its seasonal association with influenza. Infect Control Hosp Epidemiol 2010, 31:382-387.

51. Christianson S, Golding GR, Campbell J, Mulvey MR, Canadian Nosocomial Infection Surveillance Program: Comparative genomics of Canadian epidemic lineages of methicillin-resistant Staphylococcus aureus. J Clin Microbiol 2007, 45:1904-1911.

52. Loo VG, Poirier L, Miller MA, Oughton M, Libman MD, Michaud S, Bourgault AM, Nguyen T, Frenette C, Kelly M, Vibien A, Brassard P, Fenn S, Dewar K, Hudson TJ, Horn R, René P, Monczak Y, Dascal A: A predominantly clonal multi-institutional outbreak of Clostridium difficile-associated diarrhea with high morbidity and mortality. N Engl J Med 2005, 353:2442-2449.

53. Pépin J, Valiquette L, Cossette B: Mortality attributable to nosocomial Clostridium difficile -associated disease during an epidemic caused by a hypervirulent strain in Quebec. CMAJ 2005, 173:1037-1042.

54. Martin H, Willey B, Low DE, Staempfli HR, McGeer A, Boerlin P, Mulvey M, Weese JS: Characterization of Clostridium difficile strains isolated from patients in Ontario, Canada, from 2004 to 2006. J Clin Microbiol 2008, 46:2999-3004.

55. Goorhuis A, Bakker D, Corver J, Debast SB, Harmanus C, Notermans DW Bergwerff AA, Dekker FW, Kuijper EJ: Emergence of Clostridium difficile infection due to a new hypervirulent strain, polymerase chain reaction ribotype 078. Clin Infect Dis 2008, 47:1162-1170.

56. Mulvey MR, Boyd DA, Gravel D, Hutchinson J, Kelly S, McGeer A, Moore D, Simor A, Suh KN, Taylor G, Weese JS, Miller M, Canadian Nosocomial Infection Surveillance Program: Hypervirulent Clostridium difficile strains in hospitalized patients, Canada. Emerg Infect Dis 2010, 16:678-681.

57. Costa MC, Reid-Smith R, Gow S, Hannon SJ, Booker C, Rousseau J, Benedict KM, Morley PS, Weese JS: Prevalence and molecular characterization of Clostridium difficile isolated from feedlot beef cattle upon arrival and mid-feeding period. BMC Vet Res 2012, 8:38.

58. Weese JS, Rousseau J, Deckert A, Gow S, Reid-Smith RJ: Clostridium difficile and methicillin-resistant Staphylococcus aureus shedding by slaughterage pigs. BMC Vet Res 2011, 7:41.

59. Rodriguez-Palacios A, Stämpfli HR, Duffield T, Peregrine AS, Trotz-Williams $L A$, Arroyo LG, Brazier JS, Weese JS: Clostridium difficile PCR ribotypes in calves, Canada. Emerg Infect Dis 2006, 12:1730-1736.

60. Weese JS, Finley R, Reid-Smith RR, Janecko N, Rousseau J: Evaluation of Clostridium difficile in dogs and the household environment. Epidemiol Infect 2010, 138:1100-1104.
61. Blossom DB, MCDonald LC: The challenges posed by reemerging Clostridium difficile infection. Clin Infect Dis 2007, 45:222-227.

62. Snell H, Ramos M, Longo S, John M, Hussain Z: Performance of the TechLab C. DIFF CHEK-60 enzyme immunoassay (EIA) in combination with the $C$. difficile Tox a/B/II EIA kit, the triage $C$. difficile panel immunoassay, and a cytotoxin assay for diagnosis of Clostridium difficileassociated diarrhea. J Clin Microbiol 2004, 42:4863-4865.

doi:10.1186/1471-2334-13-342

Cite this article as: Faires et al.: The identification and epidemiology of meticillin-resistant Staphylococcus aureus and Clostridium difficile in patient rooms and the ward environment. BMC Infectious Diseases 2013 13:342.

\section{Submit your next manuscript to BioMed Central and take full advantage of:}

- Convenient online submission

- Thorough peer review

- No space constraints or color figure charges

- Immediate publication on acceptance

- Inclusion in PubMed, CAS, Scopus and Google Scholar

- Research which is freely available for redistribution

Submit your manuscript at www.biomedcentral.com/submit
C BioMed Central 